were reviews and $25 \%$ were other designs including mixed methods. Just over $70 \%$ were descriptive studies, and $10 \%$ were interventions or feasibility studies. Twelve RCTs were identified. 58 papers were concerned with palliative care for people with conditions other than cancer. Key areas of research were experiences or needs (23\%), services and settings (23\%), physical symptoms (22\%) and psychological or psychosocial concerns (16\%). Few papers focused on out-ofhours care, health economics or ehealth.

Conclusion The findings reveal a considerable increase in palliative care research over the last decade when compared with 44 papers identified in a similar Scottish review in 2006 and 151 papers identified in a review of Irish palliative care research in 2013. The new Scottish Research Forum for palliative and end-of-life care is now engaging with clinicians, service managers and policy-makers to facilitate understanding, use and dissemination of key implications for education, service innovation, policy and practice.

\section{0-4 MARRIED JUST IN TIME: MEANING AND MAGIC OF WEDDINGS IN A TERTIARY CANCER CENTRE}

Ros Taylor. Royal Marsden NHS Hospital Trust, London, UK

\subsection{6/bmjspcare-2017-hospice.4}

Background Discovering what matters to people when they are dying may highlight a relationship that needs formalising in the last weeks of life. Hospices have become expert at high speed last-minute weddings. But surprisingly, many weddings also take place in a tertiary cancer hospital. Over a period of nine months the palliative care team supported six weddings in the hospital. These were expertly supported by the nursing, catering, facilities and chaplaincy team, and were a well-kept secret, apart from one which made it onto national news, as the patient was a well-known journalist.

Method A retrospective analysis of notes of patients who were married in the hospital, to discover who initiated the conversation about goals of care, about marriage, documentation about the relationship and the wedding plans, whether the patient left hospital after the ceremony and where possible, the meaning of the wedding to the couple or the bereaved widow or widower.

Findings and Discussion The hospital weddings were organised superbly, always spiritual, a mixture of joy and sadness, hard to bear but with no regrets for those who lived on. The ceremonies seemed to be for love, deepening connexion, rather than financial security. In fact one new wife inherited all her partner's debts by marrying him! Half were new relationships, with previous marriages behind them, and half were partnerships of many years, that seemed important to formalise. Only one out of six patients left the hospital, and one patient died within minutes of the wedding which was shocking for all. The purchase of the rings was a particularly symbolic gesture. Wedding outfits varied from borrowed gowns from local bridal shops, to blue hospital scrubs! Jan, widow of Colin said, 'I wanted to be a widow, not someone whose partner had died.'7 Further qualitative research is planned with the bereaved partners.

\section{Parallel session 2: What can we learn from young people and prisons?}

\section{0-5 EMPTY SHADOWS: A FILM MADE BY YOUNG PEOPLE TO DEMYSTIFY DEATH AND DYING AND TO PROMOTE HOSPICE WORK}

1,2Sarah Popplestone-Helm, ${ }^{2}$ Dan Morgan. ${ }^{1}$ St Richard's Hospice, Worcester, UK; ${ }^{2}$ Royal Grammar School, Worcester, UK

10.1136/bmjspcare-2017-hospice.5

An increased understanding of death within the younger generation is crucial to the demystifying of hospice work. A more balanced and healthier view of death, dying and bereavement has been encouraged through joint working between the hospice and a local grammar school. Fifteen Year 10 pupils visited the hospice as part of their Drama GCSE; they had a formal talk on hospice work, met with a bereaved person and asked questions regarding the family's experience. A comprehensive tour of the building gave them insight into the work undertaken and of the environment. They developed a piece of live theatre called Empty Shadows which was then filmed. This film was created by the students and was filmed within the hospice itself. Pupils sensitively used the gardens, reception area, the in-patient unit and other hospice areas to act out the story. The $50 \mathrm{~min}$ film explores themes experienced by pupils whilst visiting the hospice: breaking bad news, how children understand and relate to the death of a loved one, creation of a memory box, writing letters to those who are being left behind, the importance of honesty and trust, the impact of bereavement on men, funerals, bereavement theories and the importance of support within schools and the work place. The film created from this innovative project will be used by the hospice's Family Support Team to further their work with schools and colleges. They will use the resource to enable a more balanced and healthier view of death, dying and bereavement. The film is to be shown at the Worcestershire Palliative Care Conference in July 2017. Following the film, pupils and hospice staff will answer questions, encouraging and empowering professionals to work with young people to demystify death and dying and to promote hospice work.

\section{0-6 SCHOOL IS THE LINK FOR CHILDREN FACING LOSS}

Marilyn Dyas. Trinity Hospice, Blackpool, UK

\subsection{6/bmjspcare-2017-hospice.6}

Background As an adult and children's hospice we support children (4-18 years) and their siblings through our bereavement and pre-bereavement services. We provide counselling and therapeutic groups for all types of bereavement, and counselling for children living with progressive ill-health. Supporting the Government's agenda (Department for Education, 2016) to see all schools providing access to counselling, our unique schools link service was developed to support more children, and expanded to cover any significant loss, not just bereavement. Our paid coordinator supports 74 schools by 
upskilling a member of school staff to support these children, whilst also identifying children who need specialised support with access to our trained counsellors.

Aims Targeting all children affected by grief and loss: providing education and support to school staff, the parents and families, alongside counselling and therapy programmes for pupils. Giving help closer to home, via a trusted school staff member, and helping kids keep some semblance of 'normality' in their lives, when everything else might feel as though it is falling apart. Training a link worker in every primary/secondary school with our service and offering guidance around bereavement and significant loss. Teachers are on the frontline when it comes to the emotional wellbeing of pupils, they are the crucial element in providing that stability for children struggling with loss.

Method Model of training a link worker with ongoing support from the coordinator, within each school is both cost effective but also upskilling staff.

Results Started with 46 schools, now 74, and plan to expand. Conclusion Providing teachers with extra skills they can steer a child through even the most challenging situations. Additional support from the schools link service has dramatically changed the way youngsters are helped. Many of these children would drop out of education for a time: with our schools link service, they stay in.

\section{0-7 THE IMPLEMENTATION OF PALLIATIVE AND END OF LIFE CARE STANDARDS IN SCOTTISH PRISONS}

Gail Allan. Macmillan, NHS Scotland, Scottish Prison Service

\subsection{6/bmjspcare-2017-hospice.7}

Background The Scottish Government's Strategic Framework for Action on Palliative and End of Life Care shares a vision where palliative and end of life care is available to all. With an ageing prison population, the Scottish Prison Service has to deal with more foreseeable deaths from terminal and incurable illnesses than ever before. This brings new challenges for both prison regimes and prison facilities in providing quality palliative and end of life care for those prisoners.

Aims This two-year project aims to implement palliative and end of life care standards within a prison context to ensure access to an equitable quality service.

Initial Aims of Project Introduction visits to meet with prison service and NHS staff to discuss role and introduce them to the standards of care. Objectives for each prison based on a gap analysis and identification of education and training requirements. Identify members of staff as palliative care champions. Work collaboratively with each prison to identify their palliative population.

Results All Scottish prisons have been visited and preliminary work of introduction completed with identification of key sites for implementation of tests of change. Delivered sessions on 'What is palliative and end of life care?' Developed Palliative and Supportive Care registers to support the identification of those who may benefit from palliative care. Support new multidisciplinary prison palliative care meetings. Delivery of Anticipatory Care Planning training to prison and NHS staff. Process mapping of palliative and end of life service provision in key establishment to bench mark against standards of care and evaluate further areas of change.

Next Steps
- Evaluate first year of project.

- Develop training for prisoners

- Develop an education and support platform for Palliative Care Prison champions.

- Focused engagement with other stakeholders i.e., specialist palliative care and third sector organisations.

\section{0-8 PROACTIVE COLLABORATION WITH LOCAL PRISON SERVICES}

Helen Knowles, Tina Turner. Wakefield Hospice, Wakefield, UK

10.1136/bmjspcare-2017-hospice.8

The Wakefield Hospice in common with many others, is looking to diversify its income generation strategies in order to bring in an even greater financial contribution, and to bridge the growing gap between statutory funding and the ongoing and increasing costs of service provision. In developing this collaborative project with HMPs New Hall and Wakefield, the aim is to bring about benefits for both organisations and therefore for their specific 'populations': providing useful occupation for the residents of both prisons, facilitating access to affordable clothing and improved self-esteem, and providing an opportunity for a vulnerable group to make a positive contribution to the community, specifically those requiring the care of the hospice teams. The project has begun with the establishment of a 'hospice shop' within HMP New Hall and staffed by residents, and there are plans to extend our collaborative relationship with the development of a furniture upcycling initiative at HMP Wakefield, and the production in both settings of a range of saleable items. Benefits for the hospice are clearly financial, with shop sales already in excess of those anticipated, and estimated to increase significantly when the furniture scheme is bedded in: relationships between the organisations are now excellent, and this venture has facilitated new and important links with a community group previously not in communication with the hospice. The intention is to continue to build on the early successes, and possibly use the developing source of saleable products to reach out to other hospices with an offer of sales expansion.

\section{Parallel session 3: Real world practice: referrals, access and partnerships}

\section{0-9 PRIORITISING REFERRALS TO A SPECIALIST PALLIATIVE CARE SERVICE}

Margaret Clifford, Carl Stanborough, Thomas Osborne. St Joseph's Hospice, London, UK

\subsection{6/bmjspcare-2017-hospice.9}

Introduction With increasing referrals to specialist palliative care (SPC) services at a time of limited resources, effective triage systems are essential. This community SPC service uses a 'RAG' triage system, whereby a multidisciplinary team (MDT) decides daily if referrals should be categorised as 'Red' (seen within 24 hours), 'Amber' (3 days), or 'Green' (10 days).

Aims To assess if the MDT correctly prioritises referrals according to palliative care need. 